\title{
Article
}

\section{The Effect of Reaction Conditions and Presence of Magnesium on the Crystallization of Nickel Sulfate}

\author{
Ina Beate Jenssen ${ }^{1}$, Oluf Bøckman ${ }^{2}$, Jens-Petter Andreassen ${ }^{1}$ and Seniz Ucar ${ }^{1, *(D)}$ \\ 1 Department of Chemical Engineering, Norwegian University of Science and Technology, \\ 7491 Trondheim, Norway; ina.b.jenssen@ntnu.no (I.B.J.); jens-petter.andreassen@ntnu.no (J.-P.A.) \\ 2 Glencore Nikkelverk AS, 4613 Kristiansand, Norway; Oluf.Bockman@glencore.no \\ * Correspondence: seniz.ucar@ntnu.no
}

check for updates

Citation: Jenssen, I.B.; Bøckman, O.; Andreassen, J.-P.; Ucar, S. The Effect of Reaction Conditions and Presence of Magnesium on the Crystallization of Nickel Sulfate. Crystals 2021, 11, 1485. https://doi.org/10.3390/ cryst11121485

Academic Editor: Brahim Benyahia

Received: 30 October 2021

Accepted: 29 November 2021

Published: 30 November 2021

Publisher's Note: MDPI stays neutral with regard to jurisdictional claims in published maps and institutional affiliations.

Copyright: (c) 2021 by the authors. Licensee MDPI, Basel, Switzerland. This article is an open access article distributed under the terms and conditions of the Creative Commons Attribution (CC BY) license (https:// creativecommons.org/licenses/by/ $4.0 /)$.

\begin{abstract}
Recycling of valuable metals such as nickel is instrumental to meet the need from the dramatic increase in electric vehicle battery production and to improve its sustainability. Nickel required in the battery manufacture can be recovered from the hydrometallurgical industrial process streams by crystallization of nickel sulfate. Here, crystallization of nickel sulfate is studied from an industrial point of view, investigating the effects of temperature, seeding and presence of magnesium on the formation of various solid phases for the evaluation of their potential influence on the process design. Results showed that the precipitating phase was dictated both by seed amount and reaction temperature. Transformation of metastable phases both in suspension and in a dry state was observed over time. Presence of magnesium was shown to promote formation of $\mathrm{NiSO}_{4} \cdot 7 \mathrm{H}_{2} \mathrm{O}$ in solution and increased its stability in a dry form. In their dry state, nickel sulfate that was formed in the absence of magnesium transformed towards $\alpha-\mathrm{NiSO}_{4} \cdot 6 \mathrm{H}_{2} \mathrm{O}$, whereas those precipitated in the presence of high magnesium concentrations transformed towards $\beta-\mathrm{NiSO}_{4} \cdot 6 \mathrm{H}_{2} \mathrm{O}$, indicating that magnesium inhibited the phase transformation towards $\alpha-\mathrm{NiSO}_{4} \cdot 6 \mathrm{H}_{2} \mathrm{O}$. Knowledge about various solid phases of varying crystal morphology and stability can be used as input to decisions for the best suited solid product type and how this relates to the initial conditions of the sidestreams.
\end{abstract}

Keywords: crystallization; nickel sulfate; solid phases; phase transformation

\section{Introduction}

Nickel is an important component in a wide range of materials such as stainless steel, nickel- or copper-based alloys and catalysts, crystal UV-filters, and the cathode of ion batteries [1-4]. Among these, nickel containing electric vehicle batteries (EVBs) has seen a dramatic increase in production over the last decade as a result of the environmental targets set by, amongst others, the EU [5,6]. This situation not only creates a high demand for the production of metals used in batteries, but also necessitates their efficient recycling $[7,8]$. In addition to its market value, recycling of nickel reduces the environmental pollution caused by nickel-containing waste and the $\mathrm{CO}_{2}$ footprint of the produced metal [9].

Nickel can be recycled from various sources such as spent batteries, spent catalysts, or from process streams in the hydrometallurgical industry [4,9-11]. In industrial hydrometallurgical production by electrowinning, nickel metal is produced from an electrolyte solution of nickel sulfate. Yet, in this process, significant amounts of nickel are still present in various sidestreams, such as from the purification steps and the spent electrolyte from electrowinning, from which nickel can potentially be recovered in the form of nickel sulfate salts. Due to their primary use in Li-ion batteries, production of nickel sulfate salts is expected to become the key growth area for nickel in the coming years with the rapidly growing battery sector and develop into the second-largest application for nickel after stainless steel by 2030 [12].

One method for achieving high purity nickel sulfate products from process or waste streams is crystallization $[10,11]$. A variety of techniques can be used for this purpose 
such as evaporative, antisolvent, eutectic freeze and cooling crystallization and for each technique in-depth analyses are needed to optimize yield, energy efficiency, purity and particle characteristics of the final product [13]. In this work, seeded cooling crystallization of nickel sulfate from industrially relevant solutions are investigated.

Nickel sulfate can precipitate as hydrated salts with different hydration levels ranging from mono to heptahydrates, depending on the reaction temperature [14]. Crystallization at temperatures between $5{ }^{\circ} \mathrm{C}$ to $100{ }^{\circ} \mathrm{C}$ at neutral conditions results in the precipitation of the hexa- and heptahydrates, and thus makes them the most studied nickel sulfate phases [14]. The hexahydrate form of nickel sulfate can crystallize into two polymorphs$\alpha-\mathrm{NiSO}_{4} \cdot 6 \mathrm{H}_{2} \mathrm{O}$ (retgersite) and $\beta-\mathrm{NiSO}_{4} \cdot 6 \mathrm{H}_{2} \mathrm{O}$-with different stability regions $[15,16]$. The solubility curves of nickel sulfate hexahydrates and heptahydrate are presented in Figure 1, showing the most stable hydrate form in solution as a function of temperature. The high dependency of phase stability on reaction temperature forecasts significant implications on the cooling crystallization of nickel sulfates. Both the nucleation temperature and the time frame crystals spend in mother liquor at different temperature ranges will be commanding on the crystallization pathway and the final product population. In such a complex system, where multiple possible phases can crystallize, seeding of a supersaturated solution is a good method for inducing crystallization of a desired form, and is commonly used in industrial crystallization to control the crystallized product and product size. However, seeding does not guarantee phase purity in crystal systems with high solubility and close solubility values, such as nickel sulfate salts, due to strong contributions of the kinetic factors of crystallization $[17,18]$. Moreover, phase transformation of nickel sulfate takes place also in its dry state. Crystals of the $\mathrm{NiSO}_{4} \cdot 7 \mathrm{H}_{2} \mathrm{O}$ phase decompose in air, losing water, even at room temperature [19]. At ambient conditions, nickel sulfate heptahydrate will lose one crystal water and transform into the hexahydrate form. The transition temperatures and stability order of phases in a dry state differ from the ones reported in solution $[20,21]$. At temperatures above the stability range of $\beta-\mathrm{NiSO}_{4} \cdot 6 \mathrm{H}_{2} \mathrm{O}$, the nickel sulfate can lose several crystal waters and convert into phases such as $\mathrm{NiSO}_{4} \cdot 4 \mathrm{H}_{2} \mathrm{O}$, $\mathrm{NiSO}_{4} \cdot 2 \mathrm{H}_{2} \mathrm{O}$ or anhydrous $\mathrm{NiSO}_{4}$.

The crystallization studies of nickel sulfate from industrial streams with the aim of producing battery-grade material have shown that common impurities found in such streams such as sodium, chloride and magnesium can be adsorbed or incorporated into the crystal structure. Their incorporation not only affects the purity of the product, but also can have consequences on the pathways of crystallization. Impurities present in a growth medium can influence the solubility of the crystallizing phases, and hence have significant effects on the course of reaction progression, and considerable effects on the properties of the crystal solid [18]. In the case of transformation between polymorphs or different phases, the rate of dissolution of a metastable form may decrease by the addition of specific impurities, and hence slows down the transformation towards the stable phase [17]. When the additives that will promote or inhibit certain forms of a compound are determined, it is possible to direct the system towards the desired product. Examples of this strategy can be found with L-glutamic acid, where the transformation from the metastable to the stable form can be inhibited by specific additives and thus allow kinetic factors to dominate the system [22,23]. Hence, from an industrial point of view, it is important to know how impurities in the process stream will influence the final crystallization product, in terms of properties such as purity and stability.

Having an understanding of different polymorphs or phases of nickel sulfates and transformation between these are of great importance for industrial production. Nickel sulfate hexahydrates are the preferred products over the heptahydrate form due to their lower water content. Additionally, stable crystals are favored during storage and transport, which reduces the risk of free water production and changes in crystal properties over time. Particle properties such as size, size distribution and shape effect their filterability, and thus should be controlled if possible [25]. 


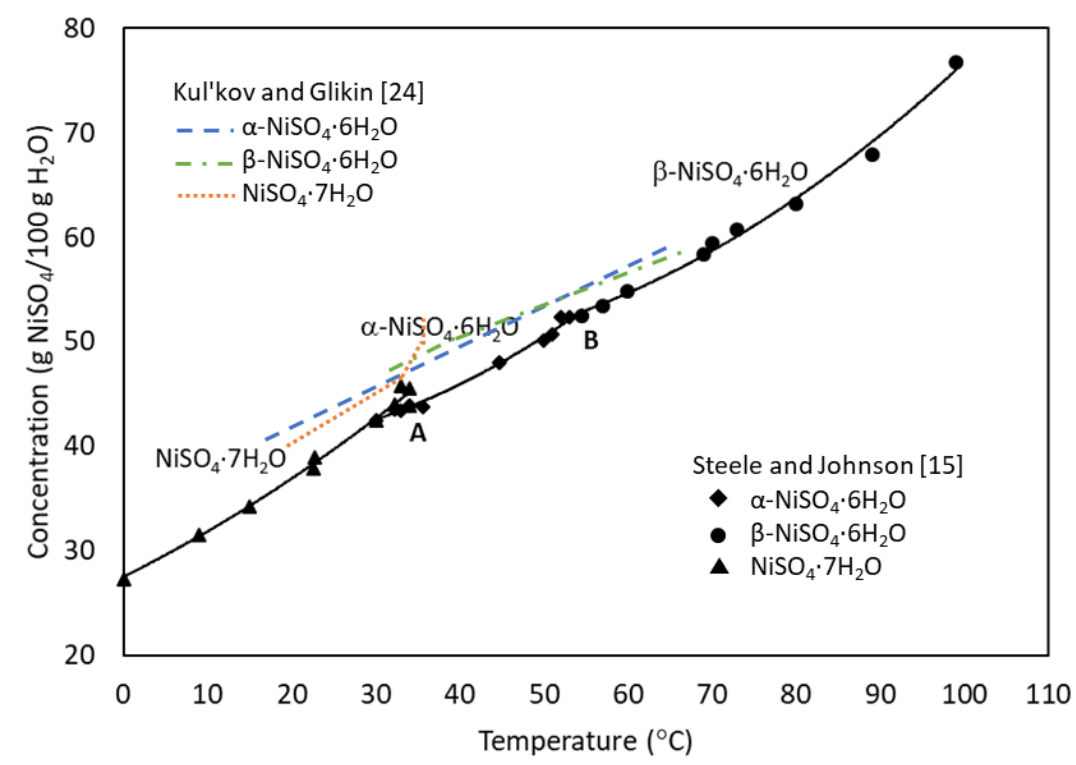

Figure 1. Solubility of nickel sulfate hydrates as a function of temperature, adapted from Refs [15,24]. Solubility curves in both studies show two eutonic points, A and B, representing the transition points for the thermodynamically most stable phase. Below $31.5-32{ }^{\circ} \mathrm{C}$, the pale green heptahydrate, $\mathrm{NiSO}_{4} \cdot 7 \mathrm{H}_{2} \mathrm{O}$ (morenosite), is the most stable phase in acid-free solutions and above this temperature nickel sulfate hexahydrate will form in solution. The transition point between the two hexahydrate polymorphs has been observed to be between $53-55^{\circ} \mathrm{C}[15,24]$. Near eutonic points precipitation of nickel sulfate salts out of their stability regions and reversable phase transformation between phases are probable. Metastable equilibria here were shown to be comparable to thermodynamic equilibria.

On the basis of the described knowledge needs, this work aims to study the cooling crystallization of nickel sulfate from an industrial point of view, at relevant temperatures for process streams, containing nickel, which could potentially be used for extracting nickel by crystallization of nickel sulfate. For this purpose, crystallization experiments seeded with $\alpha$-NSH6 are employed as a strategy to control the precipitation product. Among the nickel sulfate phases shown in Figure 1 that can be precipitated in the determined experimental range, $\alpha$-NSH6 is preferred due to its lower water content and its higher stability in storage conditions. The effects of magnesium on the crystallization and stability of nickel sulfate is investigated due to earlier work showing high levels of uptake and possible incorporation of magnesium in the crystal bulk $[4,26]$. Finally, stability of precipitated crystals both in solution and in dry state is followed, which can have practical implications on the recovery and storage of nickel salts.

\section{Materials and Methods}

\subsection{Experimental Set-Up for Crystallization Experiments}

Crystallization experiments were performed using a $100 \mathrm{~mL}$ temperature-controlled double-walled batch reactor (Figure 2), as described in detail in our previous work [26]. Proper mixing was ensured by a magnetic stirrer operating at $600 \mathrm{rpm}$ and two baffles were attached to the lid. Temperature and $\mathrm{pH}$ were logged throughout the experiments, using a $\mathrm{pH}$ probe connected to a Mettler Toledo SevenExcellence multiparameter module. The temperature of the reactor was controlled by a Julabo refrigerated/heating circulator. The temperature logging was used for observing the point of nucleation, which could be seen as a small temperature increase, due to the heat of crystallization liberated when a solute crystallizes out of a solution [17]. 


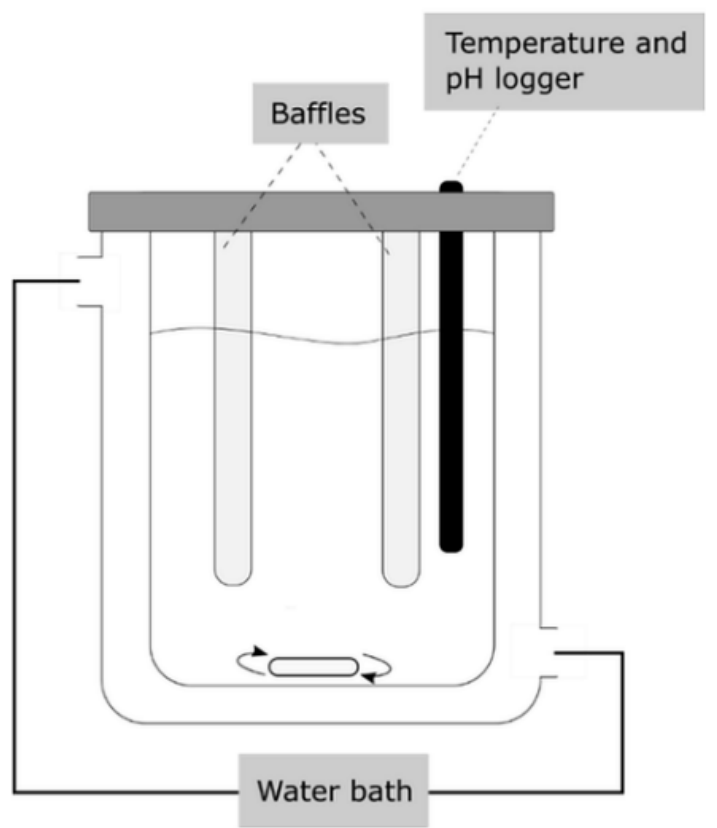

Figure 2. Sketch of the experimental set-up used for crystallization of nickel sulfate. Batch reactor, temperature-controlled by circulating water bath. Proper mixing was ensured by magnetic stirring and baffles attached to the lid.

\subsection{Experimental Methods and Characterization}

\subsubsection{Preparation of Nickel Sulfate Seeds}

In order to produce pure $\alpha-\mathrm{NiSO}_{4} \cdot 6 \mathrm{H}_{2} \mathrm{O}$ seeds, commercial nickel sulfate hexahydrate (reagent grade $\geq 98 \%$, Sigma-Aldrich, Darmstadt, Germany) was dissolved in distilled water, and was left for evaporation at $40{ }^{\circ} \mathrm{C}$ overnight $[27,28]$. The phase purity of the seeds was verified by powder X-ray diffraction (XRD) analysis and comparing the spectra with theoretical diffraction patterns of nickel sulfate hydrates (see Supplementary Information, Section A). Seeds were stored in their dry state at room temperature until further use. Their stability over storage time was confirmed by XRD analyses (Figure 3), and seeds from the same batch were used for all the seeded crystallization experiments in this work.

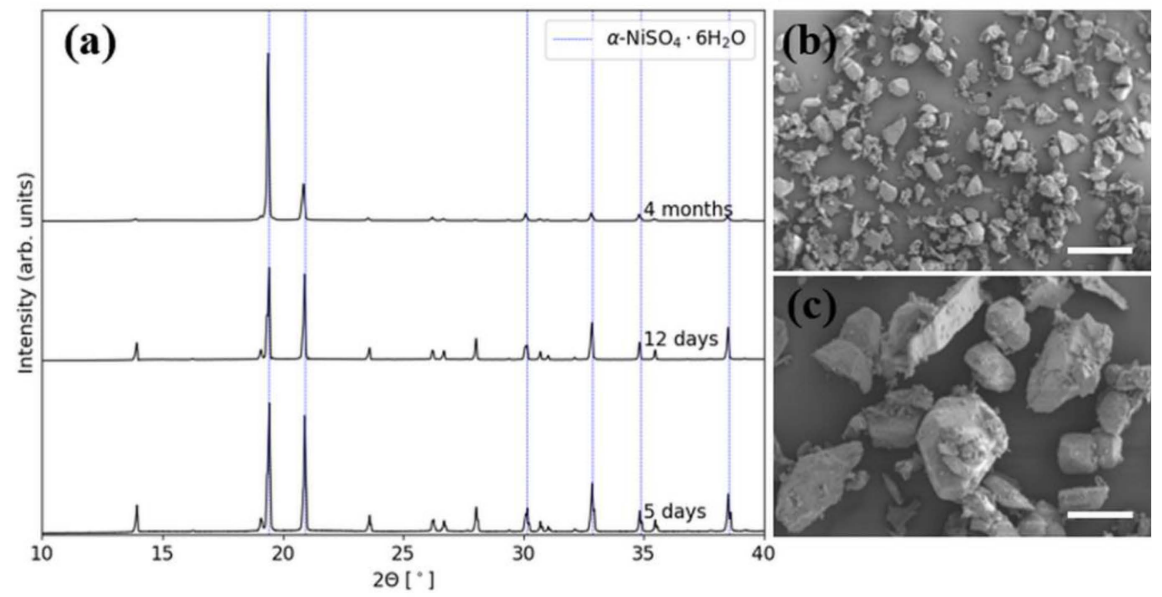

Figure 3. (a) XRD spectra of phase pure $\alpha-\mathrm{NiSO}_{4} \cdot 6 \mathrm{H}_{2} \mathrm{O}$ seeds, synthesized by evaporative crystallization at $40{ }^{\circ} \mathrm{C}$. Spectra shows pure $\alpha$-NSH at all times, with blue lines indicating the most prominent characteristic peaks. Changes in the relative intensities of the peaks were interpreted as a result of crystal alignment. (b,c) SEM micrographs of the seeds are shown at various magnifications. Scale bar: (b) $400 \mu \mathrm{m}$, (c) $100 \mu \mathrm{m}$. 


\subsubsection{Crystallization Experiments}

Seeded and unseeded crystallization experiments were conducted at two temperature values: $25^{\circ} \mathrm{C}$ and $70{ }^{\circ} \mathrm{C}$. These values were chosen based on the temperatures of nickelcontaining process streams that are potential candidates for the extraction of nickel. Initial nickel sulfate concentrations that allow seeding without spontaneous crystallization at the chosen temperatures were determined at preliminary experiments without impurities. For all the experiments performed at a low temperature $\left(25^{\circ} \mathrm{C}\right)$, the concentration of nickel sulfate was $0.53 \mathrm{~g} \mathrm{NiSO}_{4} \cdot 6 \mathrm{H}_{2} \mathrm{O} / \mathrm{g}$ solution, and at high temperature $\left(70{ }^{\circ} \mathrm{C}\right)$ the concentration was $0.70 \mathrm{~g} \mathrm{NiSO}_{4} \cdot 6 \mathrm{H}_{2} \mathrm{O} / \mathrm{g}$ solution. The chosen concentrations corresponded to the same supersaturation level with respect to the most stable $\mathrm{NiSO}_{4}$ phase at the respective temperatures. The solutions were prepared by dissolving the corresponding amounts of the nickel sulfate salt by heating, followed by cooling down to the chosen reaction temperatures at a cooling rate of $0.29^{\circ} \mathrm{C} \mathrm{min}^{-1}$ (Figure 4). An overview of the experimental conditions is given in Table 1.

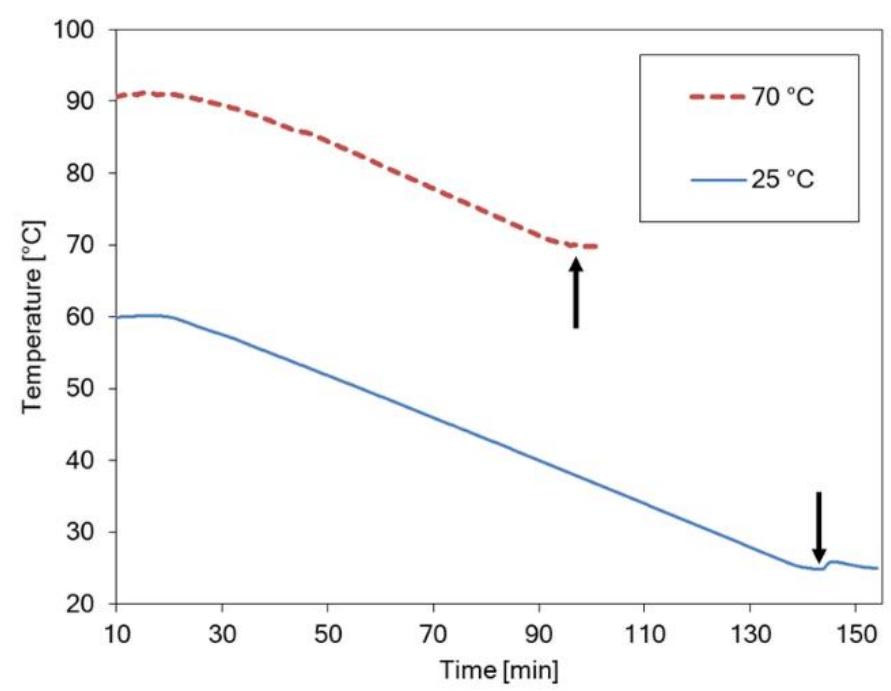

Figure 4. Temperature evolution during crystallization of nickel sulfate at temperatures 25 and $70{ }^{\circ} \mathrm{C}$. Seeds were added once the desired temperature was reached, where the arrows represent the seeding time points. The cooling rate for both cases is $0.29^{\circ} \mathrm{C} \mathrm{min}^{-1}$. Note the temperature increase in the blue curve, showing the nucleation of nickel sulfate after seed addition.

Table 1. Overview of experiments and their respective temperatures, seed amounts, and initial magnesium concentrations ( $\mathrm{mg} \mathrm{Mg} / \mathrm{g}$ total solution) in the reactor solution.

\begin{tabular}{cc}
\hline Seed Amount (g) & Mg Content (mg/g tot) \\
\hline $\mathrm{T}=25^{\circ} \mathrm{C}$ & 0 \\
0 & 18 \\
0 & 0 \\
0.2 & 5 \\
0.2 & 9 \\
0.2 & 18 \\
0.2 & 0 \\
2 & 9 \\
2 & \\
\hline $\mathrm{T}=70{ }^{\circ} \mathrm{C}$ & 0 \\
0.2 & 0 \\
2 & \\
\hline
\end{tabular}




\subsubsection{Seeded Experiments}

Once the chosen temperature was reached, nickel sulfate seeds were added to the reactor, and the suspension was left for $10 \mathrm{~min}$ before the samples were taken out for characterization to ensure sufficient crystal growth while minimizing phase transformation. Low and high seed amounts were tested, with 0.2 and $2 \mathrm{~g}$ respectively, in order to study the effect of seed amount on the final nickel sulfate product. Seeded experiments were performed in solutions both without $\mathrm{Mg}$ and with different amounts of $\mathrm{Mg}$.

\subsubsection{Unseeded Experiments}

Unseeded experiments were performed to study the behavior of the system at $25{ }^{\circ} \mathrm{C}$ without seeding. The experiments were allowed to run until nucleation was observed via an increase in temperature, and precipitates were left for $10 \mathrm{~min}$ before sampling. Unseeded experiments were not repeated at $70^{\circ} \mathrm{C}$ since the nucleation point could not be detected at this temperature.

\subsubsection{Magnesium Uptake during Crystallization}

Based on our previous results [26], magnesium was selected as the impurity of interest in this study, due to its capability to be incorporated into the nickel sulfate crystal structure. Experiments in the presence of magnesium was conducted by the addition of $\mathrm{MgSO}_{4}$ (anhydrous, ReagentPlus ${ }^{\circledR} \geq 99.5 \%$, Sigma-Aldrich) at varying concentrations to the reaction medium, using the same setup as described above.

\subsubsection{Characterization}

At the end of the experiments, small samples of the suspension were taken out from the reactor, in order to characterize the precipitated nickel sulfate. Directly after sampling, the samples were filtered, washed with ethanol and dried at room temperature in air overnight. Filtration of samples from experiments conducted at $70^{\circ} \mathrm{C}$ were performed with a preheated funnel to avoid additional crystallization on the filtration equipment. The crystal phase was determined by powder X-ray diffraction (XRD) with a Bruker D8 A25 DaVinci $\mathrm{X}$-ray Diffractometer with $\mathrm{CuK} \alpha$ radiation. All XRD analyses were performed within $24 \mathrm{~h}$ after the experiment in order to avoid phase transformations, since solid-state transition was observed when dry samples were stored for longer times. Due to the crowded XRD spectra of precipitating phases, two characteristic peaks, representing the highest intensity peaks of each nickel sulfate phase, were selected and marked in all provided data to make it easier for the readers to distinguish the produced nickel sulfate phases. The complete XRD spectra of all the relevant phases are given in the Supplementary Information, Section A. Table 2 shows the assigned peaks and the abbreviations for each nickel sulfate hydrate phase in this work. The morphology and size of the crystals was studied by scanning electron microscopy (SEM) (Hitachi S-3400 N). Light microscopy images of nickel sulfate products can be found in the Supplementary Information, Section C.

Table 2. Overview of the nickel sulfate hydrates, and their abbreviations used in this work, and selected characteristic peaks with highest intensities. The selected peaks were used for identification and comparison of products from the experiments in this work.

\begin{tabular}{ccc}
\hline Nickel Sulfate Hydrate & Abbreviations & Characteristic Peaks (2ө) \\
\hline$\alpha-\mathrm{NiSO}_{4} \cdot 6 \mathrm{H}_{2} \mathrm{O}$ & $\alpha-\mathrm{NSH} 6$ & $19.4^{\circ}$ and $20.9^{\circ}$ \\
$\beta-\mathrm{NiSO}_{4} \cdot 6 \mathrm{H}_{2} \mathrm{O}$ & $\beta-\mathrm{NSH} 6$ & $20.4^{\circ}$ and $22.3^{\circ}$ \\
$\mathrm{NiSO}_{4} \cdot 7 \mathrm{H}_{2} \mathrm{O}$ & $\mathrm{NSH7}$ & $16.7^{\circ}$ and $21.1^{\circ}$ \\
\hline
\end{tabular}

\subsubsection{Phase Transformation in Solution and in Solid-State}

The phase transformation of nickel sulfate hydrate salts was studied both in solution and in solid-state. The crystallization and solution-mediated phase transformation of nickel sulfates at chosen temperatures were followed by light microscopy (Axio Imager A1m, Zeiss, Oberkochen, Germany) via monitoring the change in crystal morphology. For this 
purpose, nickel sulfate solution was first cooled down to either $40^{\circ} \mathrm{C}$ or $70{ }^{\circ} \mathrm{C}$, and a drop of this solution was placed on a microscope glass slide. The glass slide was then placed under a microscope without further control of temperature and was monitored for $60 \mathrm{~min}$.

Phase transformation in solid-state was investigated by using washed and dried samples that were obtained from experiments depicted in Table 1. Collected samples were stored in closed glass vials at room temperature and their phase transformation was followed by analyzing selected samples with XRD after $24 \mathrm{~h}$ and up to 10 days.

\section{Results}

\subsection{Crystallization of Nickel Sulfate}

3.1.1. Effect of Temperature

Seeded experiments in additive-free solutions were conducted at $25^{\circ} \mathrm{C}$ and $70{ }^{\circ} \mathrm{C}$ by cooling the nickel sulfate solutions to establish supersaturation, then adding the seeds once the desired reaction temperature was reached.

Crystallization from solutions at $25{ }^{\circ} \mathrm{C}$ and seeded with $0.2 \mathrm{~g}$ of $\alpha-\mathrm{NiSO}_{4} \cdot 6 \mathrm{H}_{2} \mathrm{O}$, resulted in a mixture consisting of $\alpha-\mathrm{NiSO}_{4} \cdot 6 \mathrm{H}_{2} \mathrm{O}(\alpha-\mathrm{NSH} 6), \beta-\mathrm{NiSO}_{4} \cdot 6 \mathrm{H}_{2} \mathrm{O}(\beta-\mathrm{NSH} 6)$ and $\mathrm{NiSO}_{4} \cdot 7 \mathrm{H}_{2} \mathrm{O}$ (NSH7), while at $70{ }^{\circ} \mathrm{C}$ only $\beta$-NSH6 was produced, as observed from XRD analyses (Figure 5a). SEM images showed a distinct difference in crystal shape of the two products, in good accordance with the phases observed from the XRD analyses (Figure $5 b, c)$.

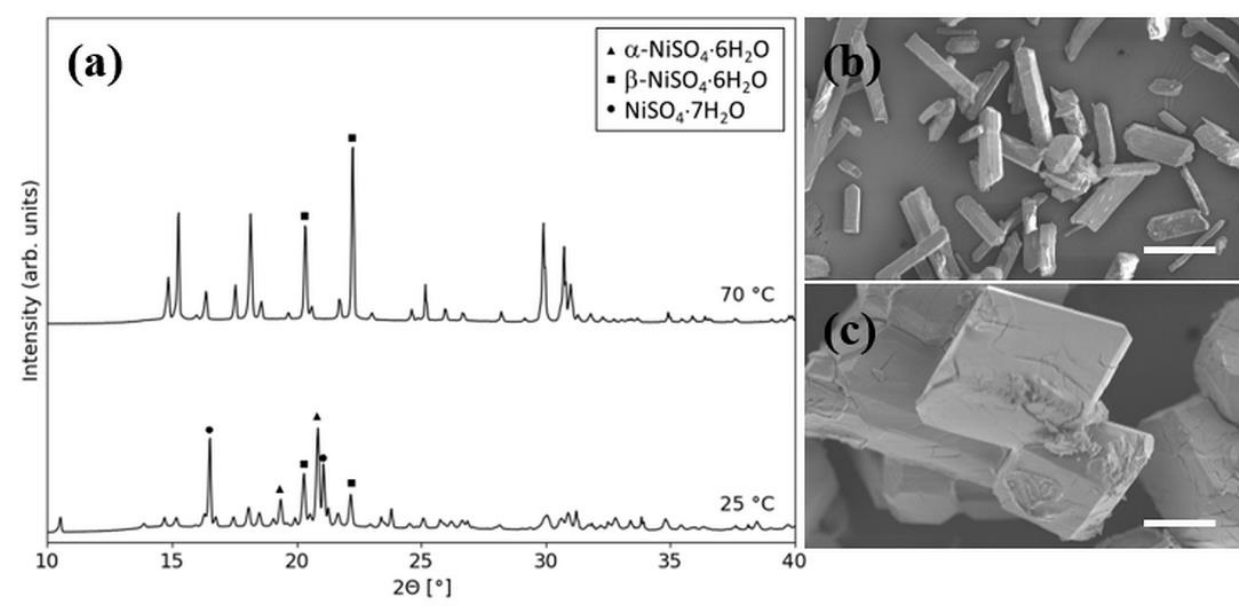

Figure 5. (a) XRD spectra of nickel sulfate crystals produced with $0.2 \mathrm{~g} \alpha-\mathrm{NiSO}_{4} \cdot 6 \mathrm{H}_{2} \mathrm{O}$ seeding and without impurities at $25^{\circ} \mathrm{C}$ and $70{ }^{\circ} \mathrm{C}$, showing the effect of crystallization temperature. (b,c) SEM images of crystals precipitated at $25^{\circ} \mathrm{C}$ and $70^{\circ} \mathrm{C}$, respectively. Scale bar: $100 \mu \mathrm{m}$.

The typical morphologies of nickel sulfate phases produced in our work correspond well with the previous observations of Kul'kov and Glikin [24]. They reported that NSH7 precipitates typically have the shape of fibrous or short-prismatic crystals, $\alpha$-NSH6 are thick plates or short-prismatic crystals, and the $\beta-\mathrm{NSH} 6$ crystals are observed as basal plates.

\subsubsection{Effect of Seed Amount}

By increasing the seed amount by a tenfold, from $0.2 \mathrm{~g}$ to $2 \mathrm{~g}$, it was possible to produce pure $\alpha$-NSH6 at $25^{\circ} \mathrm{C}$, as verified by XRD analysis (Figure 6a). SEM images showed particles of a short-prismatic shape, typical for $\alpha$-NSH6, and the long fibrous particles associated with NSH7 were absent (Figure 6a,b). On the contrary, the precipitating phase could not be altered at $70^{\circ} \mathrm{C}$ even with high seed amount, and only $\beta$-NSH6 was detected in the XRD spectrum. The plate-like crystal morphology was also maintained at higher seed amount (Figure 6c).

Unseeded experiments were also performed following the same procedure as for the seeded experiments at $25^{\circ} \mathrm{C}$. The reaction was left to proceed for $48 \mathrm{~h}$, but no crystal formation was observed in the system during this time interval. 


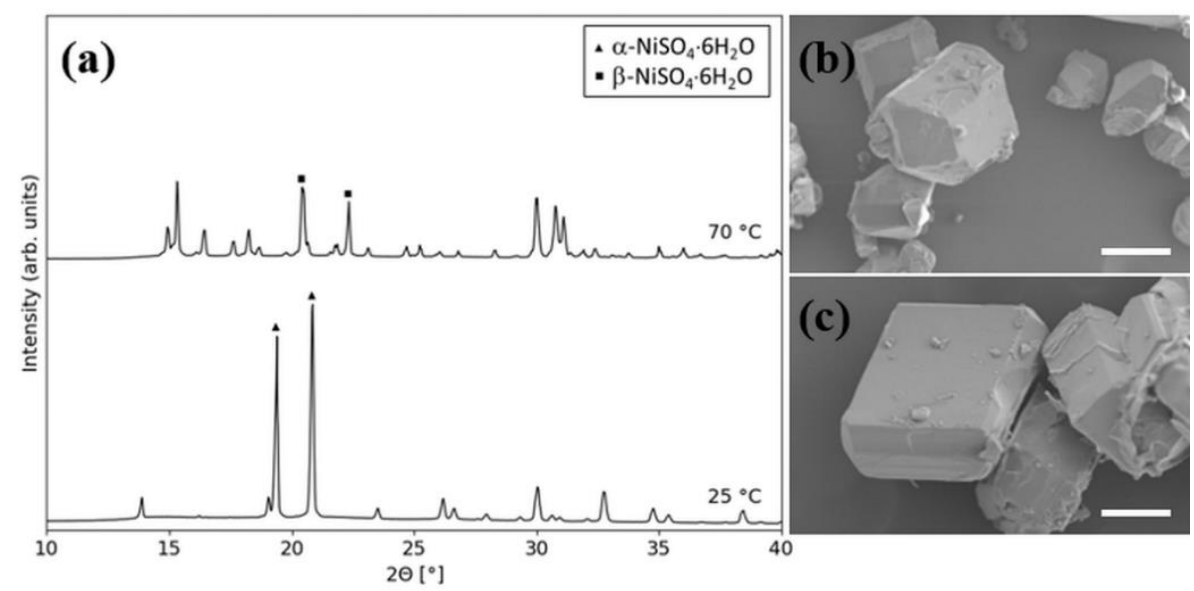

Figure 6. (a) XRD spectra of nickel sulfate phases produced at $25^{\circ} \mathrm{C}$ and $70{ }^{\circ} \mathrm{C}$, with addition of $2 \mathrm{~g}$ seeds and without impurities. (b,c) SEM images of crystals precipitated at $25^{\circ} \mathrm{C}$ and $70{ }^{\circ} \mathrm{C}$, respectively. Scale bar: $100 \mu \mathrm{m}$.

\subsection{Crystallization of Nickel Sulfate in the Presence of Magnesium}

\subsubsection{Effect of Initial Mg Content}

In order to study the effect of $\mathrm{Mg}$ uptake on the crystallization behavior of nickel sulfate, different initial concentrations of $\mathrm{Mg}$ were added in the reaction solution in experiments seeded with $0.2 \mathrm{~g}$ of $\alpha$-NSH6 at $25^{\circ} \mathrm{C}$ (Table 1). From XRD analyses (Figure 7a) it was seen that nickel sulfate precipitated with $\mathrm{Mg}$ concentrations of 0 and $5 \mathrm{mg} \mathrm{g}^{-1}$ contained a mixture of $\alpha-\mathrm{NSH} 6, \beta-\mathrm{NSH} 6$ and NSH7. At an initial $\mathrm{Mg}$ concentration of $9 \mathrm{mg} \mathrm{g}^{-1}$, the product consisted of $\beta$-NSH6 and NSH7, and with $18 \mathrm{mg} \mathrm{g}^{-1}$ only NSH7 was produced. As the initial $\mathrm{Mg}$ concentration increased in the reaction solution, the diffraction peaks of the $\alpha$-NSH6 got weaker, while the peaks of the heptahydrate phase were more pronounced. As can be seen from SEM images in Figure 7, there was no significant difference in particle shape or size for the three lower concentrations of $\mathrm{Mg}$, while the crystals were significantly bigger in the presence of high $\mathrm{Mg}$ concentration.

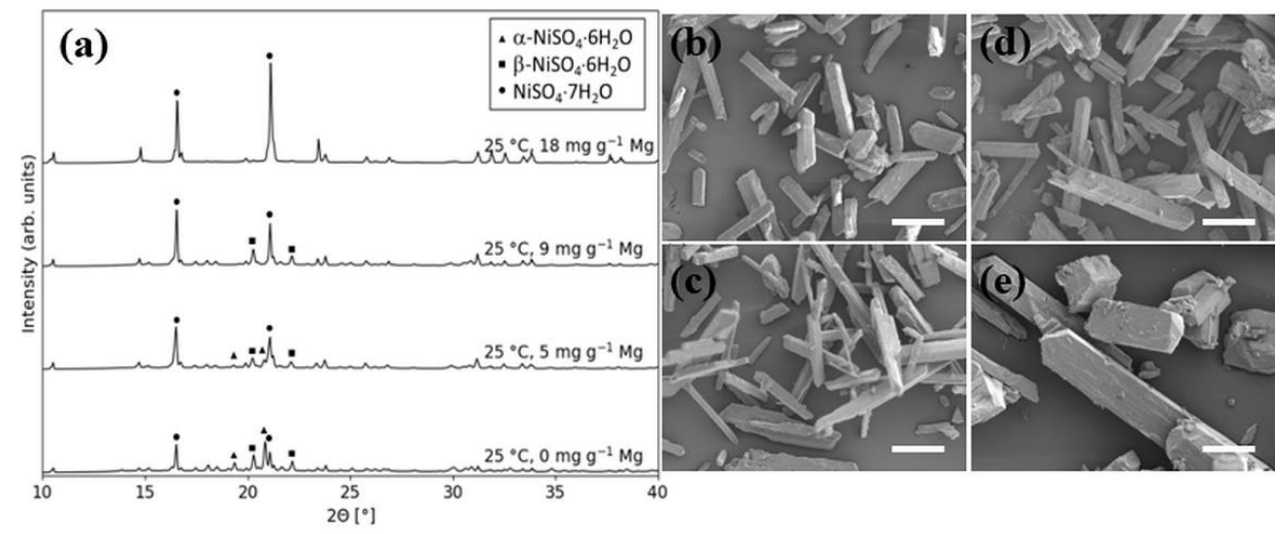

Figure 7. (a) XRD spectra of nickel sulfate phases precipitated with $0.2 \mathrm{~g} \alpha$-NSH 6 seeds at $25^{\circ} \mathrm{C}$ in the absence and presence of $\mathrm{Mg}$ at indicated concentration levels. SEM images of crystals collected from corresponding experiments; (b) no magnesium, (c) $5 \mathrm{mg} \mathrm{g}^{-1} \mathrm{Mg}$, (d) $9 \mathrm{mg} \mathrm{g}^{-1} \mathrm{Mg}$, and (e) $18 \mathrm{mg} \mathrm{g}^{-1} \mathrm{Mg}$. Scale bar: $100 \mu \mathrm{m}$.

\subsubsection{Effect of Seed Amount}

The effect of seed amount on crystallization in the presence of magnesium was tested only at a $\mathrm{Mg}$ concentration of $9 \mathrm{mg} \mathrm{g}^{-1}$ and at $25^{\circ} \mathrm{C}$. The precipitating phase and morphology of the particles did not show any changes when the seed amount was increased from $0.2 \mathrm{~g}$ to $2 \mathrm{~g}$, as seen from XRD analyses (Figures $7 \mathrm{a}$ and $8 \mathrm{a}$, respectively) and SEM images (Figures $7 \mathrm{~d}$ and $8 \mathrm{a}$ inset, respectively), showing a mixture of $\beta$-NSH6 and NSH7 crystals. 

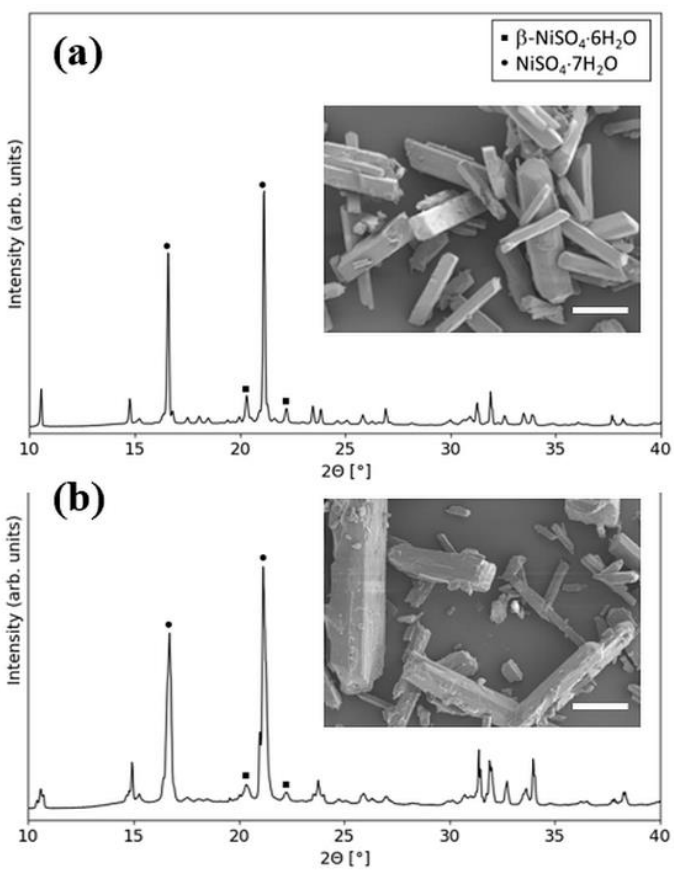

Figure 8. XRD spectra and (insets) SEM images of crystals precipitated at $25^{\circ} \mathrm{C}$ (a) in the presence of $9 \mathrm{mg} \mathrm{g}^{-1} \mathrm{Mg}$ with addition of $2 \mathrm{~g}$ seeds, and (b) in the presence of $18 \mathrm{mg} \mathrm{g}^{-1} \mathrm{Mg}$, without the addition of seeds. Scale bar: $100 \mu \mathrm{m}$.

Unseeded experiments were performed at parallel reaction conditions without $\mathrm{Mg}$ and with an initial $\mathrm{Mg}$ concentration of $18 \mathrm{mg} \mathrm{g}^{-1}$. In contrast to $\mathrm{Mg}$ free experiments, where no precipitation was observed for $48 \mathrm{~h}$, nucleation was detected during initial cooling in the presence of $\mathrm{Mg}$ by an increase of temperature at $28^{\circ} \mathrm{C}$ (see Supplementary Information, Section B), and the product was shown to consist of mainly NSH7, with weak peaks of $\beta$-NSH6 (Figure 8b). The characteristic long fibrous crystal form for NSH7 was observed by SEM (Figure $8 \mathrm{~b}$ inset).

\subsection{Phase Transformation of Nickel Sulfate Crystals}

\subsubsection{Phase Transformation in Suspension}

The phase stability of nickel sulfate in solution was investigated at low and high temperatures, without seeding. For this purpose, a small amount of solution was taken out from the reactor, placed on a microscopy glass slide and imaged at predetermined time points during $60 \mathrm{~min}$. For low and high temperature, the nickel sulfate solution was cooled to $40^{\circ} \mathrm{C}$ and $70{ }^{\circ} \mathrm{C}$, respectively, before sampling. After sampling, the glass slide was observed under the microscope for $60 \mathrm{~min}$, without further control on temperature. At low temperatures, crystals with morphologies resembling $\alpha$-NSH6 were present after 5 min of sampling, and no significant changes could be observed from the light microscopy images during $60 \mathrm{~min}$ (Figure 9a,b). It should be noted that unseeded batch experiments at $25^{\circ} \mathrm{C}$, which were also cooled down from $40{ }^{\circ} \mathrm{C}$, did not yield any crystal formation. This discrepancy can be explained by the faster cooling rate when the sample is placed on the glass slide, and the large surface provided by the glass slide, allowing nucleation to take place. At high temperatures, many crystals with varying morphologies were observed from the initial time point, and phase transformation was observed in time (Figure 9c,d). Further growth of certain crystals accompanied by the consumption of neighboring ones showed that a solution-mediated phase transformation was active. 

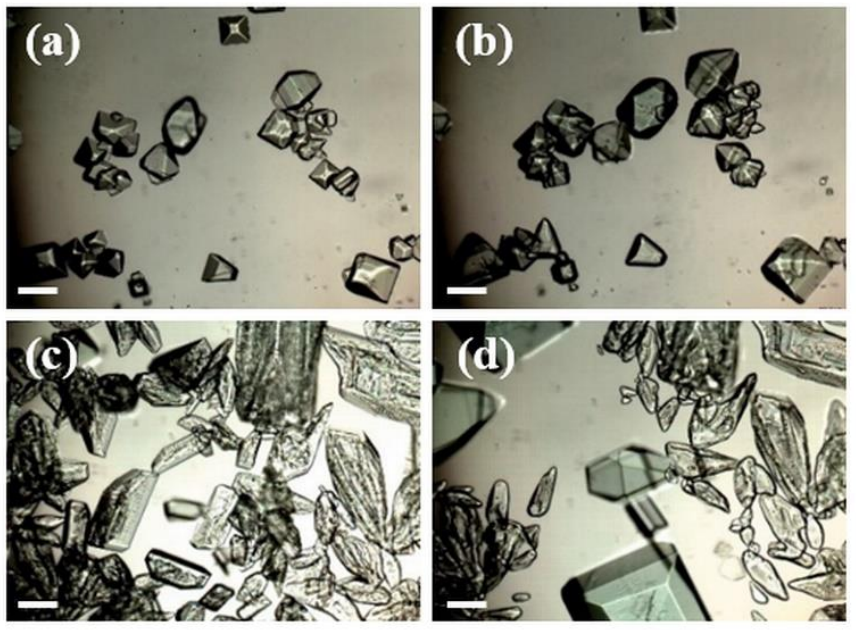

Figure 9. Nickel sulfate crystallized on microscope glass slide and imaged by optical microscope. Samples taken out: $(\mathbf{a}, \mathbf{b})$ at $40^{\circ} \mathrm{C}$ and $(\mathbf{c}, \mathbf{d})$ at $70{ }^{\circ} \mathrm{C}$, and imaged after $5 \mathrm{~min}$ and $60 \mathrm{~min}$, respectively. Scale bar: $100 \mu \mathrm{m}$.

\subsubsection{Phase Transformation in the Dry State}

From preliminary experiments, it was observed that the nickel sulfate in its dry state transforms over time when stored at room temperature. Therefore, XRD analyses were performed to follow the transformation of chosen dry samples over several days (see Supplementary Information, Section D).

For nickel sulfate produced at $25^{\circ} \mathrm{C}$ with addition of $0.2 \mathrm{~g}$ seeds and without $\mathrm{Mg}$, the $\beta$-NSH6 peaks disappeared within 7 days of storage time, the NSH7 peaks got weaker, while the $\alpha$-NSH6 peaks got stronger and new $\alpha$-NSH6 peaks were observed.

Nickel sulfate produced at $70^{\circ} \mathrm{C}$ with addition of $0.2 \mathrm{~g}$ seeds and without $\mathrm{Mg}$, showed $\beta$-NSH6 peaks disappearing over the same time period, the NSH7 peaks got weaker, while the $\alpha$-NSH6 peaks got stronger and new $\alpha$-NSH6 peaks were observed. The same trend was observed for nickel sulfate produced at $25{ }^{\circ} \mathrm{C}$ with an initial $\mathrm{Mg}$ concentration of $5 \mathrm{mg} \mathrm{g}^{-1}$. However, at $25^{\circ} \mathrm{C}$ with initial $\mathrm{Mg}$ concentration of $18 \mathrm{mg} \mathrm{g}^{-1}, \alpha$-NSH6 peaks were observed after storage for 10 days, and the heptahydrate peaks were stronger. In addition, some peaks of the $\beta$-polymorph appeared. The same trend was observed for the nickel sulfate produced in the unseeded experiment in the presence of $18 \mathrm{mg} \mathrm{g}^{-1} \mathrm{Mg}$. For nickel sulfate crystallized at $70{ }^{\circ} \mathrm{C}$, the peaks of $\beta$-NSH6 got weaker with time, and after 10 days there were also new $\alpha$-NSH6 peaks.

In summary, the dry nickel sulfate samples precipitated without $\mathrm{Mg}$ tend to transform towards $\alpha$-NSH6, while the ones with Mg content showed stable NSH7 phase and emergence of $\beta$-NSH6.

\section{Discussion}

\subsection{Effect of Temperature and Seed Amount}

In nickel sulfate crystallization, temperature plays a pivotal role in determining the final product. Within the temperature range of $0-100{ }^{\circ} \mathrm{C}$, the thermodynamic stability regions of different nickel sulfate phases are well-established. The crystalline phases of two hexahydrate polymorphs, $\alpha-\mathrm{NSH} 6$ and $\beta-\mathrm{NSH} 6$, and the heptahydrate form, NSH7, are the most stable precipitation products at different temperature ranges marked by the eutonic points, according to their solubility curves as shown in Figure 1. Yet, near the eutonic points, these highly soluble salts can precipitate and persist in solution out of their stability zones as a result of comparable effects of kinetic factors to thermodynamic drivers.

At 25 and $70{ }^{\circ} \mathrm{C}$, the most stable phases in solution are NSH7 and $\beta$-NSH6, respectively. Experiments conducted at the corresponding temperatures and with $0.2 \mathrm{~g}$ of $\alpha$-NSH6 seeds showed that the presence of the seeds was not sufficient to manipulate the system towards precipitation of the metastable $\alpha$ polymorph. XRD analyses (Figure 5) showed that for 
crystallization of nickel sulfate at $70{ }^{\circ} \mathrm{C}$, seeded with $0.2 \mathrm{~g}$ of $\alpha$-NSH6, the product consisted of pure $\beta$-NSH6. Although seeds of the $\alpha$-polymorph were added in the reaction medium, formation of the $\beta-\mathrm{NSH} 6$ at $70{ }^{\circ} \mathrm{C}$ was in good accordance with earlier findings showing that it is the most stable phase, above $53^{\circ} \mathrm{C}[15,24]$. The $\alpha$-seeds must undergo dissolution and recrystallization reactions due to the higher solubility of $\alpha$-NSH6 than $\beta-\mathrm{NSH} 6$ at this temperature. Even at a higher seed amount of $2 \mathrm{~g}$, pure $\beta$-NSH6 was produced at $70{ }^{\circ} \mathrm{C}$, verifying the high driving force in the system towards the formation of $\beta$-polymorph, which induces the phase transformation of the seed material (Figure 6). At $25^{\circ} \mathrm{C}$, our results showed that when seeded with $0.2 \mathrm{~g}$ of $\alpha-\mathrm{NSH} 6$, the crystallization product contained both the $\alpha$ - and $\beta$-polymorph of the hexahydrate, in addition to the heptahydrate form which has been reported to be the most stable phase of nickel sulfate below $35^{\circ} \mathrm{C}$. For compounds that can undergo enantiotropic transformations, metastable phases can be crystallized, before transforming to the stable phase, following Ostwald's rule of stages [17]. This might explain the presence of the two NSH6 polymorphs even though the NSH7 is the most thermodynamically stable phase at $25{ }^{\circ} \mathrm{C}$ since reaction times were limited to $10 \mathrm{~min}$. The observations of $\alpha-\mathrm{NSH} 6$ in this case can be explained by the presence of the seeds; yet, the formation of other phases must be due to additional nucleation, possibly caused by insufficient seed amounts to ensure only growth in the system $[17,29]$. When the seed amount was increased by a ten-fold, only $\alpha$-NSH6 was obtained at $25^{\circ} \mathrm{C}$. Higher seed amounts provide an increased surface area for growth [30], hence promoting growth over nucleation. It should also be noted that with both seed amounts, the total mass of final precipitates was measured to be approximately $10 \mathrm{~g}$, showing that the supersaturation consumption by relative rates of nucleation and growth was influenced by the seed amount, while the yield was not drastically affected. Some secondary nucleation was also observed for this experiment, as seen by the presence of smaller crystals in SEM images (Figure 6a,b) and from light microscopy (see Supplementary Information, Section C, Figure C.3b). These results showed that in addition to the interplay between the supersaturation value and the seed amount, the kinetics of precipitation was of paramount importance in determining the metastability regions of the three phases.

For unseeded experiments at $25^{\circ} \mathrm{C}$, without $\mathrm{Mg}$, the reaction was left for $48 \mathrm{~h}$, without any signs of nucleation taking place, neither visually nor by an increase in temperature. This indicates that the system is very stable with a broad metastable zone where spontaneous crystallization is unlikely to occur [17].

\subsection{Effect of Magnesium}

Additives can cause changes in the stability zones of crystalline phases by effecting kinetic and/or thermodynamic factors. Magnesium was chosen as the additive of interest due to its relevance in industrial streams and previous reports signaling for incorporation of $\mathrm{Mg}$ in the crystalline structure of nickel sulfate crystals [26]. Incorporation of additives can drastically affect the crystal solubility, thus the thermodynamic stability, as well as kinetic stability of metastable phases $[17,18]$.

The effect of magnesium on precipitation of nickel sulfate crystals was investigated at $25{ }^{\circ} \mathrm{C}$, in the absence and presence of varying amounts of $\alpha$-NSH6 seeds. With no magnesium present and in the absence of seeds, no crystal formation was observed even after $48 \mathrm{~h}$ in the system, whereas $\mathrm{Mg}$ additives at a concentration of $18 \mathrm{mg} \mathrm{g}^{-1}$ induced spontaneous formation of NSH7 even before reaching $25^{\circ} \mathrm{C}$ by cooling. Promotion of NSH7 formation in the presence of $\mathrm{Mg}$ was further demonstrated in the seeded experiments, where increasing amounts of $\mathrm{Mg}$ shifted the product towards higher contents of NSH7. Experiments conducted at $25{ }^{\circ} \mathrm{C}$ without $\mathrm{Mg}$ and with $0.2 \mathrm{~g}$ of seeds resulted in a mixture of nickel sulfate hydrates as shown in Figure 5. With increasing $\mathrm{Mg}$ content under same experimental conditions, we observed promotion of the diffraction peaks corresponding to NSH7 and at the highest initial concentration of $\mathrm{Mg}\left(18 \mathrm{mg} \mathrm{g}^{-1}\right)$, the product consisted of phase pure NSH7 (Figure 7). It also must be noted that, in this experimental condition nucleation occurred at $33{ }^{\circ} \mathrm{C}$ (observed by a slight increase in temperature), hence prior 
to addition of the seeds. The primary nucleation of NSH7 during cooling can explain the phase pure product and the larger crystal size (Figure 7e). Since samples were taken out 10 min after reaching $25^{\circ} \mathrm{C}$ for all experiments, the crystals nucleated during the cooling period were allowed to grow for a longer time period.

Seeded experiments with varying concentrations of $\mathrm{Mg}$ demonstrated that $\mathrm{Mg}$ promotes the formation of NSH7. Additionally, we cannot eliminate possible inhibition of the formation of hexahydrate polymorphs by $\mathrm{Mg}$ presence. Changing stability in the crystal product in the presence of additives is known. For crystallization of $\mathrm{CaCO}_{3}$ as calcite and aragonite, similar effects of the presence of $\mathrm{Mg}$ has been observed, where $\mathrm{Mg}$ is favorable towards crystallization of aragonite, due to calcite becoming more soluble [31,32]. Moreover, for L-glutamic acid, certain additives have been shown to inhibit transformation from the metastable to the thermodynamically stable phase [22,23].

\subsection{Transformation of Nickel Sulfate Hydrates in Solution and Dry State}

Different polymorphs and phases of crystalline compounds have different physical properties that can be of importance in industrial applications $[17,33]$. Thus, phase transformations of nickel sulfate particles are investigated both in solution and in the dry state, which can be significant for the production and storage stages, respectively. By taking out a small sample of the nickel sulfate solution from the reactor at $40{ }^{\circ} \mathrm{C}$ and $70{ }^{\circ} \mathrm{C}$, and immediately placing a few drops of the sample on a glass microscope slide, it was possible to follow the development of crystals by light microscopy over time. This could be a good indication of how the nickel sulfate crystals behave in solution. For these experiments, nucleation was observed within 5 min for both temperatures, whereas unseeded experiments at $25{ }^{\circ} \mathrm{C}$ did not produce any crystals. As mentioned in the previous section, this could be explained by the faster cooling rate when the sample was placed on the glass slide, and the large substrate surface. At $40{ }^{\circ} \mathrm{C}$ (Figure 9a,b), $\alpha$-NSH6 was observed, based on the short-prismatic shape of the product compared with the morphologies of the $\alpha$-NSH6 seeds (Figure 3c), $\alpha$-NSH6 produced in our previous work [26], and previous findings by Kul'kov and Glikin [24]. During the time period of observation, it could be seen that the crystals were slightly growing while maintaining their shape. At $70^{\circ} \mathrm{C}$ (Figure $9 \mathrm{c}, \mathrm{d}$ ), the particle shapes did not appear as well defined as for the sample taken out at $40^{\circ} \mathrm{C}$, but they showed resemblance to the typical plate like shape of $\beta$-NSH6 [24]. However, with time, the particles either had dissolved or the shape had changed significantly. After $60 \mathrm{~min}$, short-prismatic crystals of $\alpha$-NSH6 could be observed.

Nickel sulfate crystals in suspension have been observed to undergo transformations between the three mentioned phases during heating or cooling in the system [15]. Corresponding to the points A and B in Figure 1, the transition point between NSH7 and $\alpha$-NSH6 is around $31.5^{\circ} \mathrm{C}$, and between $\alpha$-NSH6 and $\beta$-NSH6 at $53.3^{\circ} \mathrm{C}$. From light microscopy images (Figure 9), phase transformation was observed at high temperature. Moreover, the crystallized product from experiments at $70{ }^{\circ} \mathrm{C}$, seeded with $\alpha$-NSH6, showed no indications of $\alpha$-NSH6 in the XRD spectra. This could be explained by phase transformation from $\alpha$-NSH6 to $\beta$-NSH6 in solution. Light microscopy images showed growth of crystals accompanied by consumption of neighboring crystals, indicating solution-mediated phase transformation.

In its dry state, nickel sulfate was observed to phase transform when stored as a dry powder. The phase transformations were followed by XRD analyses of chosen samples (see Supplementary Information, Section D). The general trend for samples not containing $\mathrm{Mg}$ was that with time, new $\alpha$-NSH6 peaks appeared in the XRD spectra and $\alpha$-NSH6 peaks already existing got more pronounced. Peaks of $\beta$-NSH6 got weaker with increasing storage time, and even disappeared completely in some cases. When precipitated in the presence of $\mathrm{Mg}$, nickel sulfate crystals in their dry form showed a stable NSH7 phase and the emergence of $\beta$-NSH6. Phase transformations in the dry state at room temperature followed a different pathway to that in solution, which indicates a difference in the stability regions of crystal phases [34]. While NSH7 was the most stable phase in solution at $25^{\circ} \mathrm{C}$, in 
dry conditions $\alpha$-NSH6 was favored. Earlier work shows that NSH7 loses one crystal water and transforms to $\alpha-\mathrm{NSH} 6$, which is considered to be the most stable phase in dry state in air at room temperature $[16,24,35]$. Friesen et al. [20] observed that the NSH7 transforms spontaneously at room temperature via the pathway NSH7 $\rightarrow \beta-\mathrm{NSH} 6 \rightarrow \alpha-\mathrm{NSH} 6[20,36]$. This corresponds well with the transformations we observed for samples containing no or small amounts of $\mathrm{Mg}$. On the other hand, this transformation was inhibited when crystals were precipitated in the presence of $\mathrm{Mg}$, demonstrating stabilization of NSH7. However, suppression of $\alpha$-NSH6 formation should also be considered as a possible outcome of $\mathrm{Mg}$ presence since at the highest concentration of the additive, NSH7 crystals were formed in solution transformed to $\beta$-NSH6.

\section{Conclusions}

Nickel sulfate salts show an increasing market share due to being a component of electric vehicle batteries, among other applications. Industrial hydrometallurgical nickel production by electrowinning offers a potential recovery route for nickel sulfates by precipitation since nickel metal is produced from an electrolyte solution of nickel sulfate and significant amounts of nickel are present in various sidestreams. Yet, the presence of multiple nickel sulfate hydrate phases, their metastability and significant effects of impurities necessitates detailed investigations to optimize the crystallization processes towards a desirable product. Accordingly, in this work, crystallization of nickel sulfate was investigated at $25{ }^{\circ} \mathrm{C}$ and $70{ }^{\circ} \mathrm{C}$, with different seed amounts and in the absence and presence of various initial magnesium concentrations. The results showed that seeding alone is not always sufficient to control the crystallization of nickel sulfate phases from supersaturated solutions, and the reaction temperature as well as the reaction time may dominate the final precipitate. Following the phase transformations of nickel sulfate phases both in solution and in dry state further demonstrated the difficulty of manipulating this dynamic system towards a desired stable product. Experiments conducted with various initial concentrations of $\mathrm{Mg}$ showed that its presence promotes NSH7 formation and could have inhibitory effects on the formation of hexahydrate polymorphs in solution, as well as showing significant effects on the stability of different phases in the dry state. Although crystallization of nickel sulfate salts offer an attractive strategy to obtain high purity products and efficient recycling routes, our results show that the complexity of these systems should be recognized, where in-depth studies can provide the necessary input to optimize any chosen crystallization method for process design. Future work should include the designation of potential recycling routes for nickel sulfate salts from industrial streams and optimization of crystallization processes for their relevant conditions.

Supplementary Materials: The following are available online at https:/ / www.mdpi.com/article/ 10.3390/cryst11121485/s1; (Figure SA) XRD spectra of nickel sulfate phases, (Figure SB) temperature profiles of crystallization reactions, (Figure SC) light microscopy images of particles, (Figure SD) XRD spectra and SEM images following phase transformation of nickel sulfate salts in dry state.

Author Contributions: Conceptualization, I.B.J., O.B., J.-P.A. and S.U.; Data curation, I.B.J. and S.U.; Formal analysis, I.B.J. and S.U.; Funding acquisition, J.-P.A.; Investigation, I.B.J. and S.U.; Methodology, I.B.J., J.-P.A. and S.U.; Project administration, J.-P.A.; Supervision, J.-P.A. and S.U.; Visualization, I.B.J.; Writing-Original draft, I.B.J. and S.U.; Writing-Review and editing, I.B.J., O.B., J.-P.A. and S.U. All authors have read and agreed to the published version of the manuscript.

Funding: This research was funded by the Norwegian Research Council, Yara, Glencore Nikkelverk AS, and Boliden Odda (Norwegian Research Council project number 236674).

Data Availability Statement: The data presented in this study are available on request from the corresponding author. The data are not publicly available due to confidentiality agreement with industrial partners.

Conflicts of Interest: The authors declare no conflict of interest. 


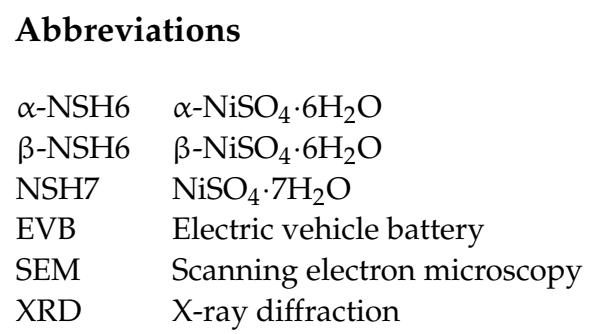

\section{References}

1. He, Y.; Su, G.; Yu, X.; Li, Z.; Huang, B.; Jang, R.; Zhao, Q. Growth of $\alpha$-nickel sulphate hexahydrate for ultraviolet filters. J. Cryst. Growth 1996, 169, 193-195. [CrossRef]

2. Thirupathy, J.; Dhas, S.S.J.; Jose, M.; Dhas, S.M.B. An investigation on optical, mechanical and thermal properties of nickel sulphate hexahydrate single crystal-A UV band pass filter. Mater. Res. Express 2019, 6, 086206. [CrossRef]

3. Volkova, E.; Demidov, A. Production of nickel sulfate single crystals in processing of nickel oxide electrodes of alkaline batteries. Russ. J. Appl. Chem. 2010, 83, 1874-1876. [CrossRef]

4. Han, B.; Bøckman, O.; Wilson, B.P.; Lundström, M.; Louhi-Kultanen, M. Purification of Nickel Sulfate by Batch Cooling Crystallization. Chem. Eng. Technol. 2019, 42, 1475-1480. [CrossRef]

5. Berckmans, G.; Messagie, M.; Smekens, J.; Omar, N.; Vanhaverbeke, L.; Van Mierlo, J. Cost Projection of State of the Art Lithium-Ion Batteries for Electric Vehicles Up to 2030. Energies 2017, 10, 1314. [CrossRef]

6. The European Commission. White Paper: European Transport Policy for 2010: Time to Decide; The European Commission: Bruxelles, Belgium, 2001.

7. Bloomberg Finance. New Energy Finance, Electric Vehicle Outlook 2017-Executive Summary. 2017. Available online: http:/ / data.bloomberglp.com/bnef/sites/14/2017/07/BNEF_EVO_2017_ExecutiveSummary.pdf (accessed on 16 July 2019).

8. Nitta, N.; Wu, F.; Lee, J.T.; Yushin, G. Li-ion battery materials: Present and future. Mater. Today 2015, 18, 252-264. [CrossRef]

9. Coman, V.; Robotin, B.; Ilea, P. Nickel recovery/removal from industrial wastes: A review. Resour. Conserv. Recycl. 2013, 73, 229-238. [CrossRef]

10. Nyirenda, R.; Phiri, W. The removal of nickel from copper electrorefining bleed-off electrolyte. Miner. Eng. 1998, 11, 23-37. [CrossRef]

11. Agrawal, A.; Manoj, M.K.; Kumari, S.; Bagchi, D.; Kumar, V.; Pandey, B.D. Extractive separation of copper and nickel from copper bleed stream by solvent extraction route. Miner. Eng. 2008, 21, 1126-1130. [CrossRef]

12. Roskill. Nickel Sulphate Outlook to 2030. 2021. Available online: https://roskill.com/market-report/nickel-sulphate/ (accessed on 25 October 2021).

13. Ma, Y.; Svärd, M.; Xiao, X.; Gardner, J.M.; Olsson, R.T.; Forsberg, K. Precipitation and Crystallization Used in the Production of Metal Salts for Li-Ion Battery Materials: A Review. Metals 2020, 10, 1609. [CrossRef]

14. Nicholls, D. The Chemistry of Iron, Cobalt and Nickel: Comprehensive Inorganic Chemistry; Elsevier Science: Amsterdam, The Netherlands, 2013; pp. 1109-1159.

15. Steele, B.D.; Johnson, F. XIII.-The solubility curves of the hydrates of nickel sulphate. J. Chem. Soc. Trans. 1904, 85, 113-120. [CrossRef]

16. Angel, R.; Finger, L. Polymorphism of nickel sulfate hexahydrate. Acta Crystallogr. Sect. C Cryst. Struct. Commun. 1988, 44, 1869-1873. [CrossRef]

17. Mullin, J.W. Crystallization; Elsevier Science: Amsterdam, The Netherlands, 2001; pp. 280-284.

18. Sangwal, K. Additives and Crystallization Processes: From Fundamentals to Applications; John Wiley \& Sons: Hoboken, NJ, USA, 2007.

19. Manomenova, V.L.; Rudneva, E.B.; Voloshin, A.E.; Soboleva, L.V.; Vasil'ev, A.B.; Mchedlishvili, B.V. Growth of $\alpha-\mathrm{NiSO} 4 \cdot 6 \mathrm{H} 2 \mathrm{O}$ crystals at high rates. Crystallogr. Rep. 2005, 50, 877-882. [CrossRef]

20. Friesen, M.; Burt, H.; Mitchell, A. The dehydration of nickel sulfate. Thermochim. Acta 1980, 41, 167-174. [CrossRef]

21. Svarovsky, L. 2-Characterization of particles suspended in liquids. In Solid-Liquid Separation, 4th ed.; Svarovsky, L., Ed.; Butterworth-Heinemann: Oxford, UK, 2001; pp. 30-65.

22. Davey, R.; Blagden, N.; Potts, A.G.D.; Docherty, R. Polymorphism in Molecular Crystals: Stabilization of a Metastable Form by Conformational Mimicry. J. Am. Chem. Soc. 1997, 119, 1767-1772. [CrossRef]

23. Sakata, Y.; Takenouchi, K. Studies on the Behaviors of Impurities on the Crystallization of L-Glutamic Acid-Part III. Influences of Some Factors on the Solubility. Agric. Biol. Chem. 1962, 26, 824-830.

24. Kul'kov, A.M.; Glikin, A.E. Replacement of nickelhexahydrite with retgersite: Polymorphic-metasomatic structures. Geol. Ore Depos. 2007, 49, 821-826. [CrossRef]

25. Bourcier, D.; Féraud, J.; Colson, D.; Mandrick, K.; Ode, D.; Brackx, E.; Puel, F. Influence of particle size and shape properties on cake resistance and compressibility during pressure filtration. Chem. Eng. Sci. 2016, 144, 176-187. [CrossRef]

26. Jenssen, I.B.; Ucar, S.; Bøckman, O.; Dotterud, O.M.; Andreassen, J.-P. Impurity Uptake During Cooling Crystallization of Nickel Sulfate; Springer International Publishing: Cham, Switzerland, 2020; pp. 191-199.

27. Kathiravan, P.; Balakrishnan, T.; Srinath, C.; Ramamurthi, K.; Thamotharan, S. Growth and characterization of $\alpha$-nickel sulphate hexahydrate single crystal. Karbala Int. J. Mod. Sci. 2016, 2, 226-238. [CrossRef] 
28. Moldoveanu, G.A.; Demopoulos, G.P. Producing high-grade nickel sulfate with solvent displacement crystallization. JOM 2002, 54, 49-53. [CrossRef]

29. Kubota, N.; Doki, N.; Yokota, M.; Sato, A. Seeding policy in batch cooling crystallization. Powder Technol. 2001, 121, 31-38. [CrossRef]

30. Chung, S.H.; Ma, D.L.; Braatz, R.D. Optimal seeding in batch crystallization. Can. J. Chem. Eng. 1999, 77, 590-596. [CrossRef]

31. Berner, R.A. The role of magnesium in the crystal growth of calcite and aragonite from sea water. Geochim. Cosmochim. Acta 1975, 39, 489-504. [CrossRef]

32. Kitano, Y. The behavior of various inorganic ions in the separation of calcium carbonate from a bicarbonate solution. Bull. Chem. Soc. Jpn. 1962, 35, 1973-1980. [CrossRef]

33. Henck, J.O.; Kuhnert-Brandstatter, M. Demonstration of the terms enantiotropy and monotropy in polymorphism research exemplified by flurbiprofen. J. Pharm. Sci. 1999, 88, 103-108. [CrossRef] [PubMed]

34. Kitamura, M. Strategy for control of crystallization of polymorphs. CrystEngComm 2009, 11, 949-964. [CrossRef]

35. Frondel, C.; Palache, C. Retgersite, $\mathrm{NiSO}_{4} \cdot 6 \mathrm{H}_{2} \mathrm{O}$, a new mineral. Am. Mineral. J. Earth Planet. Mater. 1949, 34, $188-194$.

36. Sinha, S.; Deshpande, N.; Deshpande, D. Thermal dehydration of crystallin $\mathrm{NiSO}_{4} \cdot 6 \mathrm{H}_{2} \mathrm{O}$. Thermochim. Acta 1989, 144, 83-93. [CrossRef] 